\title{
VOZES DA DIVERSIDADE: GÊNERO NO DISCURSO CINEMATOGRÁFICO
}

\author{
Dina Maria Martins Ferreira (UECE) ${ }^{1}$
}

Tibério Caminha (UECE) ${ }^{2}$

\begin{abstract}
Este artigo tem por objetivo fomentar a discussão sobre a importância do discurso cinematográfico experimental como veículo de representações sociais e simbólicas em identidades de comunidades marginalizadas. Procuramos enfatizar as dissonâncias existentes entre os discursos cinematográficos comerciais e underground nos processos de construção de sentidos que alimentam o imaginário social e determinam a performatividade do sujeito. A trilha retórica e argumentativa é atravessada por pressupostos conceituais extraídos de estudos culturais, de cinema e de gênero em conjunção com questões levantadas pela análise do discurso.
\end{abstract}

Palavras-chave: discurso cinematográfico; representação social; gênero.

This article aims to stimulate discussions about the importance of experimental cinematographic discourse as a vehicle of social and symbolic representations in the identities of marginalized communities. We try to emphasize the dissonance between commercial and underground cinematic discourses in meaning-making processes that feed the social imaginary and determine gender performativity. The rhetorical and argumentative trail is crossed by conceptual assumptions taken from gender, film and cultural studies in conjunction with the issues raised by the discourse analysis.

Keywords: cinematic discourse; social representation; gender.

\footnotetext{
$12^{\circ}$ pós-doutorado, pela Université Paris V, Sorbonne, em cotutoria com Unicamp (2009-2010); $1^{\circ}$ pós-doutorado Unicamp (2002-2003); doutorado em Linguística pela UFRJ(1995)). Pesquisadora do Centro de Atualidades e Cotidiano da Université Paris V, Sorbonne. Professora e pesquisadora do Programa de Pós-Graduação em Linguística Aplicada, Universidade Estadual do Ceará. Autora de 3 livros, organização de 4 livros, capítulo de livros, artigos nacionais e internacionais. Associada a instituições internacionais: Ipra, IGALA; e nacionais: GEL, ALAB, ABRALIN.

${ }^{2}$ Doutorando do Programa de Pós-Graduação em Linguística Aplicada, Universidade Estadual do Ceará; linhas teóricas de sua pesquisa: Análise de Discurso Crítica e Linguística Aplicada.
} 


\section{Considerações Iniciais}

Neste estudo, privilegiamos a questão de que algumas formas de construção do discurso cinematográfico são indissociáveis de políticas representacionais específicas de gênero que, por sua vez, têm por objetivo a legitimação de posições na hierarquia social. O cinema industrial e o experimental nos servem de arcabouços sobre discussões em torno de contradições existentes entre as narrativas e os modos pelos quais elas se correlacionam com o cotidiano vivido no âmbito do gênero. Nesses termos, a noção de representação social é tratada não apenas como figuração, ou mimesis, mas como instância de aporia incutida na construção de sentidos em que a práxis representacional se realiza. Portanto, em vez de apenas abordarmos cultura e arte como instrumentos de entretenimento para as massas, procuramos demonstrar que é possível estudá-las em contextos de lutas de interesses das comunidades situadas à margem do social.

Uma avaliação crítica do discurso cinematográfico torna-se relevante em razão do mesmo poder ser considerado um fenômeno simbólico capaz de generalizar e naturalizar visões de mundo particulares, não só neutralizando possíveis diferenças como também causando efeitos na reprodução das relações sociais. Nesse processo de naturalização, significações 'essencializantes' produzidas contagiam o imaginário social e espargem-se na cultura, gerando tensão entre aqueles que não se identificam com a representação imagética veiculada e aqueles que estigmatizam grupos sociais que apresentam diferença de gênero diante da matriz hegemônica da heteronormatividade.

\section{Discurso cinematográfico de gênero: perspectivas (contra-) hegemônicas}

Não se faz necessário, aqui, para nosso propósito, traçarmos um panorama histórico detalhado sobre a temática $\mathrm{LGBT}^{3}$, no entanto uma interseção entre os estudos da teoria queer, de estudos culturais e do cinema torna-se inevitável, já que o movimento politicamente organizado de liberação gay tornou visível uma cultura até então fragmentada - hoje, coesa -, e desenvolveu e desconstruiu os

\footnotetext{
${ }^{3}$ Apesar de ser uma sigla de posse do conhecimento do senso comum e da mídia, para efeitos de cuidados esclarecedores, oferecemos o significado: L de Lésbicas, G de Gays, B de Bissexuais e T de Travestis, Transexuais e Transgêneros. Já há a adoção da sigla LGBTTT que contempla as múltiplas designações do $\mathrm{T}$, que inclui travestis e transexuais.
} 
estudos de gênero, até então marcados pelas dicotomias rígidas masculino/feminino e heterossexual/homossexual, para além da matriz do 'macho branco americano' (LOPES, 2006).

Em termos históricos, adotamos o início dos anos 70 como sendo o marco que abriu espaço para uma série de contestações contra a exclusão social sofrida, na década anterior, pelos LGBTs - as rebeliões de Stonewall ${ }^{4}$ no contexto americano (final dos anos 60) e a revolução sexual difundida pela cultura hippie no Brasil (início da década de 70) ilustram nossa colocação. Emergiu, assim, uma nova perspectiva de gênero, advinda das lutas a favor da práxis, dos comportamentos e das ideias inerentes à comunidade LGBT, já articuladas em cultura própria. Tal cultura poderia desempenhar um papel de dupla função: (1) não só manifestações de identidades homossexuais serviriam para reforçar a existência de um grupo social considerado minoria - como ponto de identificação e/ou autoidentificação do Eu subjetivo com a homossociabilidade objetiva -, mas, também, reconsiderações do Outro - heterossexual ou simpatizante - em relação a estilos, e práxis social dos LGBTs, reconsiderações que, potencialmente, nulificaria a homofobia através da negociação de saberes.

No entanto, em termos culturais, ou seja, produções artísticas (o teatro, o cinema e a literatura, em especial), as questões do mundo gay - comercialização de bens simbólicos, as informações - continuam restritas ao que podemos chamar de circuito cultural underground, já que são produzidas e consumidas apenas por agentes LGBTs. As imagens a seguir ilustram representações do discurso cinematográfico, que atendem tanto à cinematografia hegemônica que atende ao entretenimento e à comercialização quanto à cinematografia underground que atende aos agentes LGBTs.

$\mathrm{Na}$ figura $1^{5}$, comprovamos a representatividade de que o discurso cinematográfico é uma narrativa com enunciados sequenciais, ou seja, um laceamento de fita heliocoidal em torno de um cilindro que contém as cabeças que descreverão a trajetória dos acontecimentos. Ou melhor, o laceamento estaria,

\footnotetext{
${ }^{4}$ As rebeliões de Stonewall foram uma série de conflitos entre a Comunidade LGBT e a polícia em Greenwich Village, Nova lorque, durante o mês de junho de 1969 , em resposta ao abuso de autoridade por parte da instituição policial contra um grupo de homossexuais frequentadores do bar Stonewall Inn - os excessos cometidos pela polícia diziam respeito tanto à violência física quanto moral (ADAM, 1995).

${ }^{5}$ Apesar da utilização de imagens nos instigar a entrar nos estudos da multimodalidade (VAN LEEUWEN, 2006), nosso foco principal é o discurso cinematográfico e a questão de gênero queer.
} 
para os elementos coesivos de um texto que juntam enunciados em um processo de coerência, o cilindro, que sustenta a organização de um discurso.

Figura 1 - Imagem representativa do discurso cinematográfico

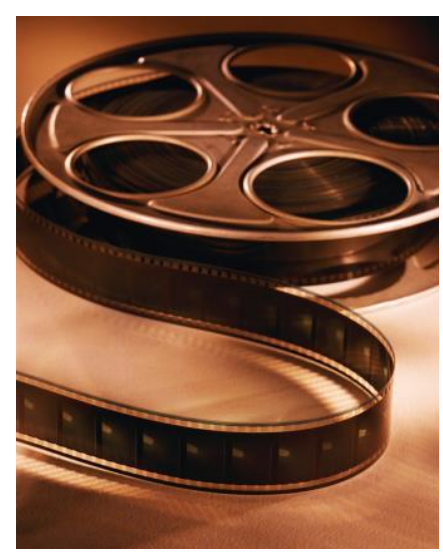

Nas figuras 2 e 3, a seguir, temos marcas modeladoras de gêneros discursivos cinematográficos. Na figura 2, temos o gênero do entretenimento com base no mercado industrial do cinema, haja vista a pipoca do entretenimento mais o próprio super-herói, ambos os elementos que sustentam a comercialidade da indústria cultural hollywoodiana. A figura 3 exemplifica e representa o gênero discursivo underground, aquele que se preocupa com a consciência e muitas vezes com a crítica contra-hegemônica. No aspecto da consciência, a imagem em preto e branco, que já exclui o glamour, mostra o cineasta focando um trabalhadorpesquisador, em que o entretenimento é um vazio não substanciado.

Figura 2 - Entretenimento e comercialização

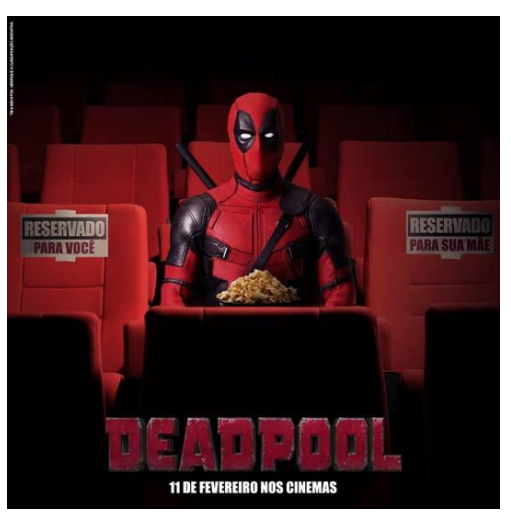

Figura 3 - Discurso cinematográfico e underground

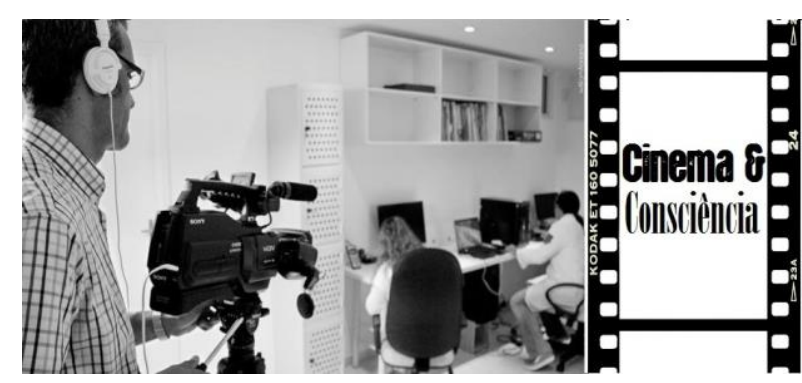


E o gênero discursivo cinematográfico underground se abre para um subgênero da ordem do anti-hegemônico, os excluídos LGBT em contrapartida à heteronormatividade - o diferente que não se enquadra nos padrões culturais vigentes. A figura 4, a seguir, é uma demonstração, de que mesmo que o diferente seja institucionalizado, ele continua sendo excluído pela diferença. Ou seja, a figura gay continua a ser uma 'fantasia' da realidade cotidiana:

Figura 4 - Festival de Cinema Gay no Rio de Janeiro, $2015^{6}$

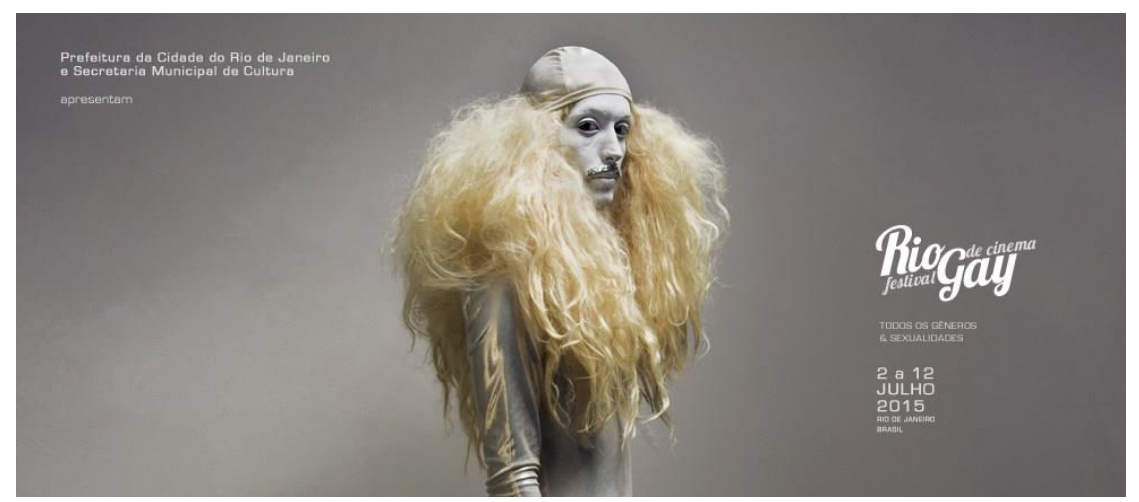

Mesmo que a figura 4 seja a representação de um festival cinematográfico gay, o sujeito do chamamento está fantasiado pela Prefeitura do Rio de Janeiro e pela Secretaria Municipal da Cultura. Se, de um lado, há uma aceitação de um fazer LGBT, de outro, há a permanência da exclusão, pois o sujeito é proclamado dentro de uma fantasia (senão grotesca), que leva à exclusão. Ou melhor, a cultura LGBT reafirma a existência de um grupo social considerado minoria, que para aparecer ao público tem de estar carnavalizado, para fazer parte das relações de poder. Para o grande público, a indústria cultural disponibiliza apenas a tradicional e mimética representação do social estereotipada, direcionando o imaginário coletivo para a inevitabilidade da cultura heteronormativa. Qualquer expressão cultural fora do padrão seria rotulada de subcultura. Torna-se evidente, diante do estatuto dado à subcultura, o papel do poder hegemônico em rechaçar as intenções libertárias e igualitárias de outrem por meio da manipulação, doutrinação e desinformação do discurso (DIJK, 2008), que, por sua vez, consolidam o segregacionismo nas relações duais de gênero ${ }^{7}$.

\footnotetext{
6 Todas as imagens estão disponíveis em: www.film.com. Acesso em 10 de fevereiro de 2016.

7 Torna-se indispensável explicarmos, aqui, que a utilização recorrente de tais dicotomias deve-se ao fato de não negligenciarmos a importância dos estudos do gênero feminino das décadas de 60 e 70 e suas contribuições - Luce Irigaray e Julia Kristeva, em especial - para o que os teóricos pós-
} 
É notório o papel da indústria cinematográfica de formar a opinião pública ao instituir uma estereotipia social - ater-se à dimensão de um social hegemônico por meio da produção de um mundo imaginário normativo - em detrimento à dimensão das diferenças individuais de gênero. Diante de tal direcionamento, o discurso cinematográfico da, então, indústria estimula a subliminação da diferenciação entre realidade e ficção e subverte a real práxis cotidiana, tornando o 'não vivido' desejável em todas as suas venturas, visto que toda representação imagética é exercida partindo de um pressuposto de simulação, ou seja, a partir de um princípio de ausência - “fingir ter [ser] o que não se tem [é]” (BAUDRILLARD, 1991, p. 9). Quando as desilusões do dia a dia alimentam a falta de esperança do espectador em um futuro com boas perspectivas, a 'realidade' construída faz nascer sua fé cega nas imagens, instigando-o viver experiências impossíveis de ele encontrar - ele, o sujeito-espectador, é capturado pelo encantamento da representação e torna-se prisioneiro do mundo da aparência, do sensível, da imagem e do simulacro (MACHADO, 2011). Ou melhor, o sujeito torna-se dependente da heteronomia através da simulação de um mundo à parte, postulado, construído e composto ${ }^{8}$ - um parasita tecnológico do celuloide ávido por tudo aquilo que o simulacro tem a lhe oferecer.

Em termos do gênero, e tendo em vista o discurso cinematográfico queer ${ }^{9}$ como um discurso de oposição e de contrariedade à heteronormatividade, podemos sugerir que a natureza da indústria comercial cinematográfica giraria em torno de uma visão sexista de mundo que legitima uma 'ordem', onde não há espaço para a pluralidade, senão para a multidimensionalidade, de expressão de gênero dos sujeitos, na medida em que as narrativas de suas produções reforçam os papéis sociais de gênero heteronormativos. Daí, afirmarmos que a temática gay contrapõe-se ao cinema de gênero - gênero em um sentido sócio-identitário

estruturalistas - Judith Butler, por exemplo - definiram de teoria queer no início dos anos 90 . Ou seja, temas como sexo, gênero e desejo abordados em primeira instância nos estudos feministas são postos em analogia com a diferença e a derivação tratadas em segunda pela Teoria Queer, sendo, por conseguinte, tais campos dialéticos.

8 Obviamente, estamos tratando a grande audiência em termos de 'massa' sem tomar em consideração certas características distintivas - tais como a criticidade e a autonomia individual que configurariam o público pequeno e especializado, senão crítico, pois é o conteúdo do discurso cinematográfico disponibilizado à totalidade indistinta o objeto de nossa argumentação.

${ }^{9}$ A teoria queer (queer theory), é uma teoria sobre o gênero que afirma que a orientação sexual e a identidade sexual ou de gênero dos indivíduos são o resultado de um construto social e que, portanto, não existem papéis sexuais essenciais ou biologicamente inscritos na natureza humana, antes formas socialmente variáveis de desempenhar um ou vários papéis sexuais. Trata-se de uma teoria crítica ao caráter imutável e a-histórico do ato de nomear os corpos, que identifica o sexo como algo anterior à cultura (cf. LOURO, 2004). 
(homem e/ou mulher). Nesses termos, ratificamos nossa inferência de que as questões de ordem sexual ${ }^{10}$ em filmes comerciais são objetivadas de acordo com categorizações hegemônicas, postuladas como verdades universais, mesmo que o cotidiano da vida comum revele outra realidade, contraditória a categorizações hegemônicas que negam a emergência das categorias discretas (ou individuais) (BAGEMIHL, 1999). Um exemplo da indústria comercial sexista que legitima uma 'ordem' está na figura 5, que alimenta os sonhos e o simulacro de uma vida fantasiosa (alegria, sedução na dança), e a figura 6 seria a representação da excludência da ordem estabelecida (dois jovens com expressão de tristeza).

Figura 5 - Sedução na dança, representação coletiva da alegria entre pares heterossexuais

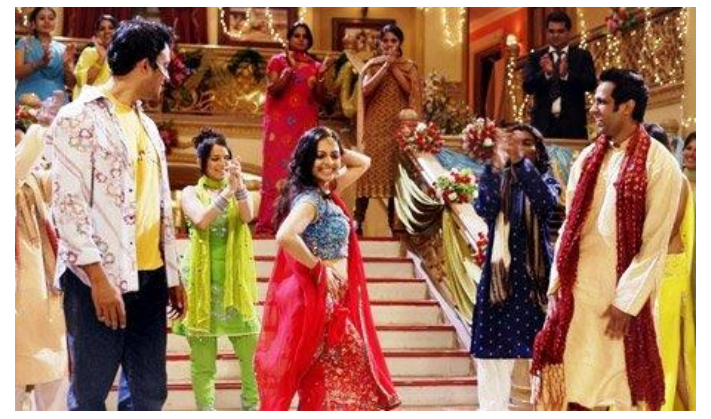

Figura 6 - Par homossexual pensativo, no ostracismo

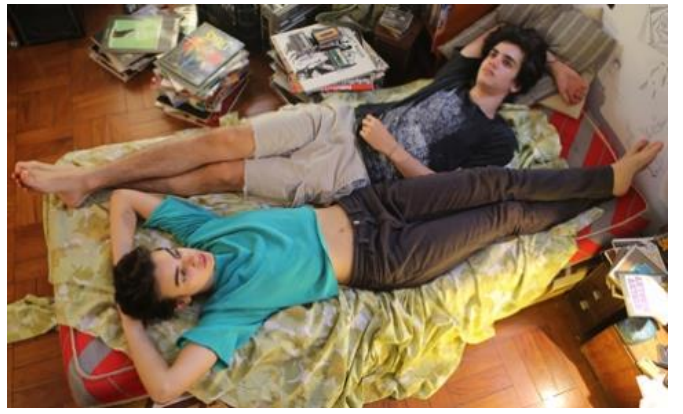

Significação Discursiva: Construção da estereotipia e representação social

Os estudos da significação discursiva e situacional apontam para a compreensão de que a arquitetura social dá-se por meio dos mais diversos usos da linguagem no processo de comunicação intersubjetiva (OLIVEIRA, 2006). Ou seja, a linguagem não é mais vista como uma mera ponte de informações entre os mundos objetivo e subjetivo - possibilitando, assim, a interpretação de tudo o que existe no exterior ao indivíduo -, mas a própria realidade mundana é analisada a partir da perspectiva de uma construção discursiva resultante da interação social. A ação humana não é mais tida como um ato individual e arbitrário, mas fundamenta-se

10 Ao utilizarmos termos da ordem do "sexual", "sexualidade", fica registrado que estamos nos referindo a "gênero", como uma construção cultural (sem negar o aspecto corporal inerente a desejos e afetos, que para muitos pensadores são da ordem do fisiológico [e não necessariamente colados ao biológico]). 
em regras e normas coletivas, senão consensuais (OLIVEIRA, 2006). Em outras palavras: tudo o que se vê (o belo e o feio), se sente (o bem-estar e o mal-estar) e se julga (o certo e o errado) são percepções de mundo construídas pelo uso linguístico no processo de interação em um contexto social específico, senão matriz aprisionante - onde linguagem e práxis são indissociáveis para a construção da significação.

$\mathrm{Na}$ expressão interação está subentendida uma correspondência entre os sujeitos envolvidos que possibilita a aproximação com a comunicação. Tanto assim que as relações sociais são construídas com base naquilo que é comum a todos (sexo, raça, idade etc.) - ou tendo como referência as semelhanças linguísticas, culturais e biológicas -, mesmo sendo redutíveis às relações de poder (THOMPSON, 1995), pois cada grupo performatiza sua própria significação, tanto na prática discursiva quanto na social. Daí as tensões sociais motivadas pelo preconceito (a causa) e pela discriminação (a consequência) que resulta em segregação entre comunidades distintas. Em meio à zona de oposições sociais, os fenômenos simbólicos (a narrativa fílmica, a imagem, em nossa discussão) são criados para estabelecer as relações de dominação através da luta pelo significado (SCHULMAN, 2010). Logo, há uma urgência para a construção de significado (MOSCOVICI, 2010), pois é um determinado sentido que legitima um grupo ao mesmo tempo em que não reconhece um outro.

Todavia, a significação está muito atrelada à imaterialidade e é necessário pô-la ao alcance do sensível para que exerça influência em lugares de sociabilidade na qualidade de ponto de referência sócio-identitário. A materialização de uma abstração - de um pensamento em imagem ou de um som em signo - diz respeito a um dos processos mais intrigantes dos quais os círculos de poder servem-se para subjugar a opinião das massas, porque é por meio dessa ação que a representação social (a imagem concreta ${ }^{11}$ ) torna-se a própria realidade vivida (agora, uma ideia e uma palavra palpável) (MOSCOVICI, 2010). E é no momento em que a objetivação do irreal torna-se a substância do real, e ideia e palavra tornam-se inseparáveis da imagem, que a representação é tida como realidade, mesmo que aceita e tornada como costumeira na práxis (MOSCOVICI, 2010). Portanto, é a prática social (no caso, o discurso cinematográfico) que estabelece a conexão perfeita entre

\footnotetext{
11 Mais uma vez, ratificamos nosso foco: as imagens se fazem presentes neste artigo como parte ilustrativa da narrativa discursiva cinematográfica, pois ratifica a substância do real na representação social.
} 
concretude e abstração, pois o uso contínuo do figurativo, recheado de valores prescritivos, desloca a representação da autoridade que a criou e a situa na esfera pública como trivialidade consensual.

As representações sociais fundam a estereotipia - elas são ingredientes importantes na sopa cultural que constitui o self individual e coletivo pela homogeneização de significações. Uma vez que a produção simbólica dá-se na instância da autoridade e resulta em cultura, inferimos que a identidade social de sujeitos é construída na heteronomia com ameaça de ostracismo para todos aqueles que apresentam diferenças (BUTLER, 1993). Em outras palavras, o marginal, o estranho e o anárquico são construídos no interior das relações de poder que excluem a diferença, porque tais relações determinam uma ação social através do controle sobre o discurso, ao ministrar no imaginário coletivo doses diárias de uma fórmula previsível de prescrições (LIPOVETSKY, 2004) - as informações.

Quando o conjunto das condições e influências sociais a que está exposto o sujeito baseia-se na legitimação da heterossexualidade como norma cultural, não é necessária uma ação direta da hegemonia para determinar a exclusão, pois o próprio imaginário coletivo não reconhece qualquer outra expressão de gênero como 'familiar'. O preconceito e a discriminação contra o queer - o subversivo - é justificado pela falta de discernimento das massas, entre o que é dito como natural e o que é cultural, visto que as significações resultantes da produção simbólica são naturalizadas em âmbito social no momento em que são vinculadas a uma fonte de validação (a Verdade, a Justiça, Deus, o Absoluto etc.) (COSTA, 2011) e, como tais, tornadas inquestionáveis. Ademais, há o fato de que a produção em massa de discursos tendenciosos, aliada à alta rotatividade de sua difusão nos diversos corredores da vida comum, previne a formação de um dissenso que ameace a autoridade, ou até mesmo as representações que denotam sua presença, em razão da consumação do bem simbólico ser determinada pela sua disponibilização.

Essa problemática nos faz questionar o papel desempenhado pela cultura e pela arte como criadoras de estereótipos abertos à crítica social, em que as representações de gênero em tensão com as estilizações hegemônicas dão-se por meio da injúria, do lugar-comum e da imitação cômica da diferença - o que relega a lésbica, o gay, o bissexual, o travesti e o transgênero ao plano do subalterno (SPIVAK, 2010). Em nossa argumentação, os discursos cinematográficos não são 
tidos apenas como representações ou reflexos das instituições e relações sociais, mas como fenômenos simbólicos estruturantes, porquanto é através deles também que se dá a própria construção, ou constituição, da sociedade e sua cultura, da determinação dos posicionamentos ideológicos do sujeito e das filiações coletivas (MCLUHAN, 1996; FAIRCLOUGH, 2001; SHOHAT; STAM, 2006). A partir do momento em que a simulação sociocultural dá aparência de realidade apenas à experiência androcêntrica, faz-se necessária a desconstrução de gêneros como categorias fixas, pois a exploração da opinião pública não apenas fomenta o preconceito que resulta em violências físicas e simbólicas, mas também torna visível o descaso da autoridade para com os movimentos minoritários em prol da igualdade de direitos.

Em equivalência, reconhecemos que a criação do estereótipo no discurso cinematográfico de gênero tem uma função crítico-social, porque põe o cliché em evidência para discussão, revela que as minorias não têm controle sobre sua própria representação e "enfatiza uma luta política e teórica contra a repetição de imagens negativas em favor da necessidade de imagens positivas" (LOPES, 2006, p. 382). Ou seja, a representação imagética contém em si o sentido e o contrassentido que possibilitam tanto a persuasão e a dissuasão das massas quanto à fragmentação do sentido passivador e alienador pelas massas (BAUDRILLARD, 1991). Além disso, os elementos apagados na construção do estereótipo têm o poder de desconstruir as posições hegemônicas inscritas nele pela contradição e pela debilitação de sentidos. O que é subliminar, oculto e latente no discurso cinematográfico é tão significativo quanto o que é expresso, o dito conduz ao nãodito, porquanto o tipo de relação que o espectador estabelece com o discurso cinematográfico é fator determinante para sua rendição ou resistência ao conteúdo da mensagem. Nesse aspecto, temos que dar atenção ao grau de distanciamento intelectual e político do sujeito e ao posicionamento da comunidade ao qual ele faz parte, pois tanto os indivíduos quanto os grupos podem se identificar uns com os outros na base de semelhanças ou de diferenças comuns (SHOHAT; STAM, 2006) e, em paralelo, com a representação na tela. São essas especificidades sociais e culturais e individuais e coletivas que fixam o espectador não só ao conceito fundamentalista e essencialista de 'massa' (grande audiência) como também ao de público pequeno e especializado (THOMPSON, 1995), como se não houvesse saída para tais classificações, um meio-termo. 
Então, como iniciar um processo de mudança social se os próprios discursos constituintes da sociedade priorizam o olhar masculino, objetivam o corpo feminino e estigmatizam as formas de vida queer?

A luta pela autorrepresentação é um fenômeno inerente às comunidades que são colocadas à margem da sociedade e diz respeito ao direito do excluído de “falar por si mesmo” (SHOHAT; STAM, 2006). A 'afirmação do si mesmo' é amparada nos estudos pós-estruturalistas que se opõem ao essencialismo que permeavam as questões de identidade e a autorização para qualquer indivíduo ou grupo falar em nome do outro, mesmo que sua posição não seja a de vítima da opressão, como se as identidades sociais fossem construídas com base em essências fixas e a diferença fosse uma determinação natural, e não cultural (SHOHAT; STAM, 2006).

Mas outra indagação surge. Em tempos de globalização em que se desencadeiam os processos de desinstitucionalização, descentralização e individualização do sujeito pós-moderno (HALL, 2006), é válida uma "ação afirmativa" (SHOHAT; STAM, 2006) no que tange à representação e à identidade queer, se estão em constante performatividade pela/na subversão das dicotomias de gênero?

Em primeira instância, a resposta é sim, pois, embora o queer ainda explore as inúmeras possibilidades de 'ser' e ainda não seja um sujeito constituído na história e no discurso social, é necessário que busque pela legitimação de sua posição e pelo reconhecimento da diferença em termos não marginalizantes através da 'objetivação' simbólica (materialização) de sua existência para abandonar o campo da incerteza e da inarticulação (MOSCOVICl, 2010), mesmo que em seguida o multiculturalismo imploda as identidades e fragmente os sujeitos estabelecidos na representação. Nesse ínterim, precisamos ter em consideração que a representação social também não é estanque, mas está sempre em movimento e aberta ao diálogo. Se o queer apropria-se do direito de falar por si mesmo no primeiro momento, a negociação de saberes tornada possível pela representação em si (agora, uma ordem do discurso) dá espaço para todos falarem lado a lado em um jogo de identificações cruzadas, sem sobreposições do eu ao outro (SHOHAT; STAM, 2006) - o que rasura as fronteiras bem definidas das categorizações que segregam ou hierarquizam gêneros. Como resultado da ação afirmativa, as relações de poder tornam-se negociáveis e renegociáveis, porquanto 
são vulneráveis ao questionamento e à subversão. É clara, então, a importância das políticas representacionais e identitárias no combate ao preconceito e à discriminação, porque elas alojam o 'estranho' em grupos sociais reconhecíveis, senão 'familiares'.

\section{Vozes da diversidade: do discurso hegemônico ao experimental}

Não podemos ser imprudentes e estabelecer a inexistência de vestígios de uma subcultura gay e suas representações anteriores ao evento Stonewall - o fato em si de haver um local de homossociabilidade chamado Stonewall Inn já entrevê referência, identificação e autoidentificação que se traduzem em comunidade e signos alusivos -, mas é indiscutível que a coesão entre os elementos préexistentes, que resultou em uma homocultura, deu-se a partir da explosão do movimento homossexual no fim dos anos 60 (ADAM, 1995; LOPES, 2006). Para essa cultura resistir ao tempo, tornou-se crucial a criação de instrumentos simbólicos (a arte, o cinema, a literatura etc.) que garantiram sua preservação - tais instrumentos, por sua vez, são formas de inscrição do conhecimento, da ética, da estética e de outros hábitos e costumes dos membros que compõem a totalidade distinta.

No que tange ao discurso cinematográfico, a indústria hollywoodiana sempre esteve fechada ao aprofundamento da temática gay, dando prioridade à (re)afirmação do gênero masculino em produções cheias de símbolos fálicos e combates bélicos que denotam altos níveis de testosterona e de adrenalina, empenhando-se na construção de uma Esparta pós-moderna nas telas com homens viris e musculosos e mulheres frágeis e submissas (em especial nas décadas de 70 e $80)^{12}$. Assim sendo, uma alternativa para as vozes silenciadas da diversidade foi o investimento em um segmento do mercado fílmico à margem da indústria comercial, ou seja, o circuito cultural underground.

\footnotetext{
12 Ver os filmes: Apocalypse Now (Francis Ford Coppola, 1979); Platoon (Oliver Stone, 1986); First Blood (Ted Kotcheff, 1982). Nota-se, por meio desses exemplos, a relação direta entre a figura do homem (a objetivação imagética) e o patriotismo exacerbado (uma abstração idealizada) que resulta na referência à identidade nacional - o macho branco americano (a representação simbólica) - e na naturalização de um sistema de poder articulado com base na opressão masculina e heterossexista.
} 
As potências dessa outra forma de fazer cinema tornam-se reconhecíveis na profusão de festivais e mostras audiovisuais que despontam a cada ano tanto na América do Norte quanto na América do Sul, e que são justificadas pela oferta de uma nova experiência ao público e pela crítica ao violar as representações hollywoodianas de sociedade no que se refere a gênero, raça e classe (KELLNER, 2001; FRANÇA, 2006). O circuito de filmes underground não está apenas a serviço dos excluídos, mas também aparece como uma opção para o espectador adulto ${ }^{13}$ que deseja um entretenimento mais substancial e que abandonou as salas de cinema convencionais. A diferença da construção discursiva cinematográfica liberal está em sua estreita relação com o cotidiano comum. Esse tipo de discurso cinematográfico brota em um campo minado de tensões sociais, com significações prescritivas e sem compromisso algum com o cotidiano, mas, contudo, ele nos deixa a par da desarmonia entre o real e o ficcional em contextos de homogeneização (nas produções comerciais), ao disponibilizar narrativas plurais fora do padrão happy end e dentro de um modelo cru, crítico e reflexivo (KELLNER, 2001; FRANÇA, 2006).

Se a indústria hollywoodiana apresenta a lésbica, o gay e o transgênero como caricaturas exóticas, indicando que tais representações são verdadeiras, o cinema liberal decalca do real essas formas de vida e as humanizam em suas afetividades, expectativas, mazelas, medos e violências, contestando a substancialidade do estereótipo. Podemos, então, qualificar o cinema underground como um cinema de resistência? Sim, porque é uma reação das minorias contra a normatização social imposta pelos discursos comerciais de gênero (KELLNER, 2001; FRANÇA, 2006). Talvez, o malefício para a hegemonia conservadora seja a possibilidade de questionamento sobre 'o que realmente se é'. As identidades pós-modernas não são fixas e limitadas, mas inacabadas, fragmentadas, contraditórias e abertas (HALL, 2006), o que coloca em contratempo qualquer tentativa de essencialismo justificado por determinações biológicas e trans-históricas. Eis o que o homem pósmoderno é: uma identidade cambiante - filho de lugar nenhum, mas de 'entrelugares', criatura mutante construída na experiência híbrida e multicultural (BHABHA, 1998).

\footnotetext{
13 Não nos baseamos apenas no número de anos vividos pelo indivíduo quando nos referimos ao espectador adulto, mas também no nível espiritual em que as atitudes, a socialização e a estabilidade afetiva do sujeito são avaliadas de acordo com o estado de adaptação ao seu próprio meio.
} 
A legitimação de que a sociedade é heterogênea, uma colcha de retalhos em constante via de fazer, tira as rédeas das mãos de qualquer autoridade exercida em fundamentalismos, em razão do cidadão não identificar-se mais com essa forma de poder, porquanto toda política democrática (e não liberal) ${ }^{14}$ acolhe o princípio das diferenças no qual não há lugar para a imposição, e sim para o consenso. Talvez, aí, a intolerância às diferenças ser o estopim da explosão de movimentos minoritários.

Nesse cenário, o discurso cinematográfico de resistência dá indícios de forças e tensões sociais reais - tais como as perspectivas queer e a femininista - que não podem ser negligenciadas em um momento de descrença em instituições de poder inflexíveis, uma vez que suas narrativas desconstroem outros discursos constituintes, criados com base na durabilidade, ao indagar as contradições entre tradição sociocultural e contexto imediato na experiência do sujeito (KELLNER, 2001). Logo, a resistência não fica constrangida à tela, pelo contrário, contagia o indivíduo e, por meio dele, é disseminada no cotidiano vivido em performatividades múltiplas (pela linguagem e pela interação, em especial), dando vazão à mudança social.

No que toca ao LGBT, o discurso cinematográfico apresenta sua identidade ao público não apenas em seus aspectos linguísticos (o dialeto utilizado pela comunidade, por exemplo), mas também em sua corporalidade (as maneiras pelas quais utiliza seu corpo como um instrumento para relacionar-se com o mundo), fazendo de seu estilo de vida uma expressão cultural facilmente reconhecível - o estranho torna-se familiar. Também, não podemos desconsiderar as importantes contribuições das microcomunidades marginalizadas na formatação da cultura de referência ${ }^{15}$, de onde inferimos que quanto maior a orquestração de vozes e modos de ser impressos na cultura das massas mais rica ela será (KELLNER, 2001). Nesse sentido, o universo LGBT aponta grandes possibilidades para o campo dos estudos culturais, pois, estando situado em um instante da história no qual se originou o

\footnotetext{
${ }^{14}$ Chamamos a atenção para o sentido de liberalismo em contrapartida ao de democracia, pois enquanto aquele determina que todos são iguais e têm as mesmas chances, esta apregoa que todas as vozes podem ser ouvidas, mesmo que para alguns seja uma posição utópica em sua realização.

15 Explicamos, aqui, que utilizamos a expressão cultura de referência como sinonímia do termo macrocultura (cultura nacional), em razão de procurarmos enfatizar a importância da questão da referência na constituição das identidades sociais em nossa argumentação. Lembramos, também, que a ideia de cultura nacional trata-se de uma tentativa de representar a coletividade através de uma 'pseudo-unificação' e homogeneização de sentidos, portanto, não toma em consideração a diferença - ou melhor, ela assimila os significados desarmônicos por meio de uma apropriação, articulando-os em seu próprio contexto de significação.
} 
termo metrossexualidade, quebra-se qualquer paradigma fundamentado apenas na experiência masculina.

O MIX Brasil ${ }^{16}$ reflete a introdução definitiva do estilo de vida queer na sociedade do consumo, porquanto as políticas de afirmação pública da comunidade LGBT não foram às únicas consequências das rebeliões de Stonewall, houve também uma verdadeira mercantilização de formas culturais homossexuais que favoreceram a inserção da homotextualidade no campo das artes (LOPES, 2006) e a aceitação das expressões de estética gay no comércio, dentre outras coisas. A partir de 1995, ser gay tornou-se ser cool $^{17}$ no Brasil, em especial para aquela geração que se despojou de referências sexistas no vestuário, nas formas do corpo e nos comportamentos, adotando um modo de ser polissêmico e livre de rótulos (homossexual, heterossexual ou bissexual, no caso) (SIMÕES; FACCHINI, 2009). A abertura à experimentação sexual sugerida pela cultura hippie, e embargada pela epidemia da AIDS nos anos 80, ganhou novo fôlego em uma juventude disposta a explorar o erotismo em algumas de suas variações sem ancorar-se em classificações preexistentes. Além disso, as novas identidades que surgiram naquela década testificaram que a submissão à experiência gay é uma questão subjetiva individual e particular -, não uma determinação sociocultural de caráter inclusivo ou exclusivo. Ou seja, a práxis do gênero e seu papel social não pode ser avaliado fora de um contexto performativo irredutível à norma e à repetição (BUTLER, 1993).

Com efeito, o cinema experimental desempenhou um papel crucial nesse passo significativo que a sociedade brasileira deu em relação à compreensão do gênero do Outro, emergindo o prisma da criticidade ao olhar-espectador até então ofuscado pelas representações hollywoodianas de gênero.

\footnotetext{
16 Em outubro de 1993, São Paulo tornou-se a primeira cidade do Brasil a sediar um festival de cinema e vídeo dirigido ao público LGBT, o I Mix Brasil da Diversidade Sexual, com o apoio do Departamento de Cinema do Museu da Imagem e do Som. O MIX Brasil trata-se de uma versão nacional do New York Lesbian and Gay Experimental Film Festival (NYLGEFF, também conhecido pela sigla MIX NYC) - um circuito cultural underground cujas atividades giram em torno da produção de curtas-metragens experimentais sobre a temática gay.

17 Ser legal [tradução nossa]. Cool é uma gíria americana difícil de conceituar de uma forma fixa, mas pode ser interpretada como significante de um tipo específico de estilo, comportamento, atitude e aparência influenciado pelo, e fruto do, Zeitgeist (em português: espírito da época, do tempo, ou sinal dos tempos). Uma das características que singularizam tal expressão é a mutabilidade inata ao seu significado - o que é considerado cool depende de um contexto histórico específico e varia entre culturas.
} 


\section{Considerações Finais}

Essa breve reflexão pôs em destaque algumas questões sobre o discurso cinematográfico que acreditamos ser indispensáveis para a desmistificação do sistema de valores e crenças socialmente construído e disseminado pelas mediações. Alguns pontos colocados em nossa argumentação podem parecer contraditórios, diante do fato de acreditarmos na necessidade da autorrepresentação para os grupos excluídos ao mesmo tempo em que rejeitamos qualquer abordagem essencialista. Ou seja, recorrer a uma "ação afirmativa” não seria cair nas mesmas categorias desacreditadas? (SHOHAT; STAM, 2006). Mas sabemos que, por vezes, a sobrevivência a situações contingenciais demanda um tipo de “essencialismo estratégico" (SPIVAK, 2010) - é ele que nos conduz a uma ação social ética, mesmo que corroendo aos poucos paradigmas socioculturais duráveis. Discutimos também alternativas de leituras do estereótipo, cada uma delas dizendo respeito à crítica desconstrutivista - o que reforça nossa hipótese de que a mudança para uma sociedade mais inclusiva dá-se pelo questionamento do raciocínio reducionista que nos encaixa em gêneros prescritivos e inegociáveis. Sobretudo, procuramos atentar para a compreensão de que nós, os espectadores, não somos os produtos finais de uma máquina de homogeneização social. Ainda

somos capazes de executar ações sociais e humanas corretas em relação às diferenças, sem a determinação das representações dominantes de um comportamento mímico.

\section{Referências}

ADAM, B. D. The rise of a gay and lesbian movement. Michigan: Twayne Publishers, 1995.

BAGEMIHL, B. Biological exuberance: animal homosexuality and natural diversity. New York: St. Martin's Press, 1999.

BAUDRILLARD, J. Simulacros e simulação. Tradução de Maria João da Costa Pereira. Lisboa: Relógio d’Água, 1991. 
BHABHA, H. K. O local da cultura. Tradução de Myriam Ávila, Eliana Lourenço de Lima Reis e Gláucia Renate Gonçalves. Belo Horizonte: Editora UFMG, 1998.

BUTLER, J. Bodies that matter: on the discursive limits of "sex". New York: Routledge, 1993.

COSTA, N. B. da. Música popular, linguagem e sociedade: analisando o discurso literomusical brasileiro. Curitiba: Appris, 2011.

DIJK, T. A. v. Discurso e poder. Tradução de Judith Hoffnagel, Ana Regina Vieira, Leonardo Mozdzenski, Benedito Gomes Bezerra, Rodrigo Castro e Karina Falcone. São Paulo: Contexto, 2008.

FAIRCLOUGH, N. Discurso e mudança social. Tradução de Izabel Magalhães. Brasília: Editora UnB, 2001.

FRANÇA, A. Cinema de terras e fronteiras. In: MASCARELLO (Org.), Fernando. História do cinema mundial. Campinas, São Paulo: Papirus, 2006, p. 395-412.

HALL, S. A identidade cultural na pós-modernidade. Tradução de Tomaz Tadeu da Silva e Guacira Lopes Louro. $11^{\mathrm{a}}$ ed. Rio de Janeiro: DP\&A, 2006.

KELLNER, D. A cultura da mídia - estudos culturais: identidade e política entre o moderno e o pós-moderno. Tradução de Ivone Castilho Benedetti. São Paulo: EDUSC, 2001.

LIPOVETSKY, G. Metamorfoses da cultura liberal: ética, mídia e empresa. Tradução de Juremir Machado da Silva. Porto Alegre: Sulina, 2004.

LOPES, D. Cinema e gênero. In: MASCARELLO (Org.), Fernando. História do cinema mundial. Campinas, São Paulo: Papirus, 2006.

LOURO, G. L. Um corpo estranho: ensaios sobre sexualidade e teoria queer. Belo Horizonte: Autêntica, 2004.

MACHADO, A. Pré-cinemas e pós-cinemas. $6^{\mathrm{a}}$ ed. São Paulo: Papirus, 2011.

MCLUHAN, M. Os meios de comunicação como extensões do homem. Tradução de Décio Pignatari. 8. ed. São Paulo: Cultrix, 1996.

MOSCOVICI, S. Representações sociais: investigações em psicologia social. Tradução de Pedrinho A. Guareschi. $7^{\mathrm{a}}$ ed. Rio de Janeiro: Vozes, 2010.

OLIVEIRA, M. A. de. Reviravolta linguístico-pragmática na filosofia contemporânea. 3. ed. São Paulo: Edições Loyola, 2006.

RICOUER, P. O si-mesmo como um outro. Tradução Luci Moreira Cesar. Campinas: Papirus, 1991. 
SCHULMAN, N. O centre for contemporary cultural studies da Universidade de Birmingham: uma história intelectual. In: SILVA (Org.), Tomaz Tadeu da. O que é, afinal, Estudos Culturais? 4. ed., Belo Horizonte: Autêntica Editora, 2010.

SHOHAT, E.; STAM, R. Crítica da imagem eurocêntrica. Tradução de Marcos Soares. São Paulo: Cosac Naify, 2006.

SIMÕES, J. A.; FACCHINI, R. Na trilha do arco-íris: do movimento homossexual ao LGBT. São Paulo: Editora Fundação Perseu Abramo, 2009.

SPIVAK, G. C. Pode o subalterno falar? Tradução de Sandra Regina Goulart Almeida, Marco Pereira Feitosa e André Pereira. Belo Horizonte: Editora UFMG, 2010.

THOMPSON, J. B. Ideologia e cultura moderna: teoria social crítica na era dos meios de comunicação de massa. Rio de Janeiro: Vozes, 1995.

VAN LEEUWEN, T.; KRESS, G. Reading images: the grammar of visual design. 2. ed. London; New York: Routledge, 2006. 